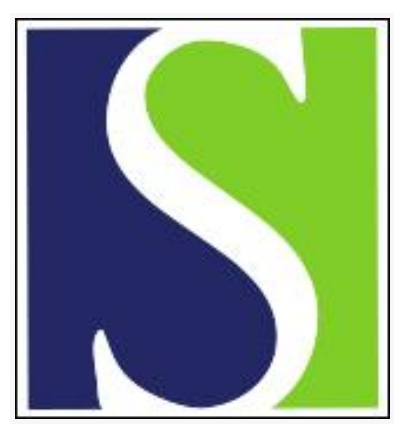

Scand J Work Environ Health 1987;13(4):334-336

https://doi.org/10.5271/sjweh.2045

Issue date: Aug 1987

Physiological methods used in Japan for the diagnosis of suspected hand-arm vibration syndrome.

by Matoba T, Sakurai T

Affiliation: Department of Environmental Medicine, Kurume University School of Medicine, Japan.

This article in PubMed: www.ncbi.nlm.nih.gov/pubmed/3324313

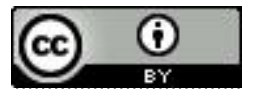




\title{
Physiological methods used in Japan for the diagnosis of suspected hand-arm vibration syndrome
}

\author{
by Tsunetaka Matoba, MD, Tadayoshi Sakurai, MD'
}

\begin{abstract}
MATOBA T, SAKURAI T. Physiological methods used in Japan for the diagnosis of suspected handarm vibration syndrome. Scand J Work Environ Health i 3 (1987) 334-336. In the pathogenesis of handarm vibration syndrome, vibration affects the peripheral system, especially the circulatory, nervous, and musculoskeletal systems. Medical questionnaires, physical examinations, and laboratory tests are used to diagnose the hand-arm vibration syndrome. The laboratory tests are satisfactory diagnostic aids for detecting slight disorders of the peripheral circulatory, nervous, and musculoskeletal systems. Peripheral circulatory function tests include skin temperature measured by a thermistor under specific temperature conditions, the nail compression test, and the cold provocation test $\left(10\right.$-min immersion in cold water at 5 or $\left.10^{\circ} \mathrm{C}\right)$. To assess peripheral nervous function, tests for the pain and vibration senses are included. Peripheral musculoskeletal function tests consist of grip strength, pinch strength and tapping counts. These physiological tests are applied in worker screening twice a year. These tests have been authorized by the Ministry of Labour since 1973. Several criteria for the tests, although not authorized, are widely used. The diagnostic implication of each separate test may be low. Consequently, some laboratory tests should be evaluated, along with medical questionnaires and physical examinations, in the diagnosis of suspected handarm vibration syndrome.
\end{abstract}

Key terms: cold provocation test, grip strength, nail compression test, pain sense, pinch strength, skin temperature, tapping test, vibration sense.

The hand-arm vibration syndrome, induced by the long-term use of vibratory tools, tends to have a protracted clinical course despite adequate treatment $(2,4)$. The most important aspect with respect to treatment is to diagnose the vibration syndrome as early as possible and to treat patients in an early, less severe stage of the disorder. Vibration syndrome is a disease entity consisting not only of injuries to the peripheral systems but also of disorders of the central nervous system, especially the autonomic nervous system $(3,5)$. In the early stage, however, injury mainly occurs in the peripheral circulatory, nervous, and muscular systems. Accordingly, a physician's attention should be focused on the peripheral systems in the diagnosis of suspected hand-arm vibration syndrome.

In this paper, we give an overview of the physiological tests which have been authorized by the Ministry of Labour for the diagnosis of suspected hand-arm vibration syndrome in Japan since 1973.

\section{Peripheral circulatory function}

Skin temperature is greatly influenced by environmental factors such as room temperature and humid-

\footnotetext{
1 Department of Environmental Medicine, Kurume University School of Medicine, Kurume, Japan.
}

Reprint requests to: Professor T Matoba, Department of Environmental Medicine, Kurume University School of Medicine, 67 Asahi-machi, Kurume 830, Japan. ity, wall temperature, airflow in a room, and seasonal changes. Before the beginning of the skin temperature test, the subject is kept for $30 \mathrm{~min}$ in a room where the temperature is maintained at $20-23^{\circ} \mathrm{C}$. Smoking is prohibited for at least $1 \mathrm{~h}$ before the test. Skin temperature on the back of the middle phalanx of fingers $2-5$ is measured by a thermistor. A healthy man shows a temperature of $30^{\circ} \mathrm{C}$ or more. Abnormal values are rated as + (less than $\left.30^{\circ} \mathrm{C}\right),++\left(28^{\circ} \mathrm{C}\right.$ or less $)$, or $+++\left(26^{\circ} \mathrm{C}\right.$ or less $)(6,9)$.

In the nail compression test, the second, the third, and the fourth finger is pressed by the thumb and index fingers of an examiner for $10 \mathrm{~s}$. The evaluation is made according to the time needed for the nail to regain its color after its release (10). The normal value is $2.0 \mathrm{~s}$ or less. Abnormal values are rated as + (over $2.0 \mathrm{~s}),++(2.5 \mathrm{~s}$ or less $)$, or $+++(3.0 \mathrm{~s}$ or less $)$. The disadvantage of the nail compression test is that the force of the compression and the evaluation of the time needed for the nail to regain color tend to vary according to the examiner's skill and experience. However, this test reflects vascular reaction in a larger area than does the skin temperature test.

\section{Peripheral nerve function}

The peripheral nerve function tests include pain sense and vibration sense of the second, third, and fourth fingers. Pain sense in the dorsum of the middle phalanx 
of the second to fifth finger is measured by a needletype of pain meter with successively graded (by weight $1-10 \mathrm{~g}$ ) needles (gauge 23 in size). The pain threshold is obtained by the minimum weight at which the examinee feels pain. The upper limit of the normal value is evaluated to be $3 \mathrm{~g}$. Abnormal values are rated as $+(5 \mathrm{~g}$ or more $),++(10 \mathrm{~g}$ or more $)$, or $+++(15 \mathrm{~g}$ or more) $(6,9)$.

Vibration sense is considered to be the threshold of the perception of vibration administered to the tip of the second, third and fourth finger on the palm side of the hand by a vibration sensimeter (Rion AU-01A). Vibration at 125 and $250 \mathrm{~Hz}$ is administered with the intensity of -10 to $40 \mathrm{~dB}$ in steps of $2.5 \mathrm{~dB}$. Recently, measurements with $125 \mathrm{~Hz}$ alone have been accepted to represent the vibration sense; the vibration sense is mediated by pacinian corpuscles above approximately $60 \mathrm{~Hz}$ and by Meissner (touch) and Merkel (pressure) receptors below this value. The normal value of the intensity is $5 \mathrm{~dB}$ or less. Abnormal values are rated as + (7.5 dB or more), $++(12.5 \mathrm{~dB}$ or more), or $+++(17.5 \mathrm{~dB}$ or more $)(6,9)$.

\section{Peripheral musculoskeletal function}

Peripheral musculoskeletal function tests consist of grip strength, pinch strength, and tapping tests. The momentary force of grip strength is determined by the greatest value of the first and second trials. The normal value shows $45 \mathrm{~kg}$ or more in strength.

The tapping test consists of the number of taps the subject can perform with the second or third finger as fast as possible for $10 \mathrm{~s}$, using a tapping meter (Tokyo Iryoki MPS-703). The normal value is 45 taps or more $(6,9)$.

The pinch strength test is carried out by pinching the arm of the pinch meter between the thumb and the index or middle finger. The normal value of the thumb/index pinch strength is $5 \mathrm{~kg}$ or more.

\section{Cold provocation}

\section{Rewarming activity}

In the cold provocation test, one hand is immersed to the wrist in 5 or $10^{\circ} \mathrm{C}$ water for $10 \mathrm{~min}$. After the test, the recovery of skin temperature is observed for $10 \mathrm{~min}$. Until around 1975, the cold provocation test was performed at a water temperature of $5^{\circ} \mathrm{C}$. During hand immersion in $5^{\circ} \mathrm{C}$ water, some subjects complain of chest tightness, finger pain, and other symptoms (1). Therefore, at present, water at $10^{\circ} \mathrm{C}$ is recommended instead. A significant correlation has been found between the methods at 5 and $10^{\circ} \mathrm{C}$ for the skin temperature and the nail compression tests after immersion $(7,8)$.
The evaluation is done according to the following formulas:

$$
\begin{aligned}
\text { recovery activity } & =\frac{1}{3}\left[\left(\mathrm{~T}_{11}-\mathrm{T}_{10}\right)+\frac{\mathrm{T}_{12}-\mathrm{T}_{10}}{2}\right. \\
- & \left.+\frac{\mathrm{T}_{13}-\mathrm{T}_{10}}{3}\right]^{\circ} \mathrm{C} / \mathrm{min}
\end{aligned}
$$

and

rate of rewarming at 5 and $10 \mathrm{~min}=$

$$
\frac{\left(\mathrm{T}_{15} \text { or } \mathrm{T}_{20}\right)-\mathrm{T}_{10}}{\mathrm{~T}_{0}-\mathrm{T}_{10}} \times 100 \%,
$$

where the subscripts are the times from the start of immersion.

The recovery must amount to at least $30 \%$ at $5 \mathrm{~min}$ and $60 \%$ at $10 \mathrm{~min}$ to be considered normal. Recovery of less than $30 \%$ at $5 \mathrm{~min}$ and of less than $60 \%$ at $10 \mathrm{~min}$ is defined as abnormal. With one of the rates abnormal, the assessment is that of a border case.

\section{Nail compression and vibration sense tests}

The nail compression and vibration sense tests are performed on the second, third, or fourth fingers immediately after $10 \mathrm{~min}$ of immersion in cold water and after 5 and $10 \mathrm{~min}$ of removal of the hand from the water. In the vibration sense test, a vibration frequency of $125 \mathrm{~Hz}$ is used because the sensitivity of the skin is highest at this frequency. Abnormal values in the nail compression test are $3.0 \mathrm{~s}$ or more immediately after $10 \mathrm{~min}$ of immersion. After 5 and $10 \mathrm{~min}$ of immersion, $2.0 \mathrm{~s}$ or more is considered abnormal $(6,9)$. The abnormal values of the vibration sense test are $17.5,12.5$ and $10.0 \mathrm{~dB}$ or more at 0,5 , and $10 \mathrm{~min}$ after the end of immersion, respectively $(6,9)$. The pain sense test has not been recommended because the skin, swollen by immersion, is easily injured with a needle.

\section{Application of the tests}

An example of the application of the tests used in the diagnosis of the hand-arm vibration syndrome follows. An examination was made of 15 workers with suspected hand-arm vibration syndrome (table 1). Cases $1-10$ were diagnosed as having the hand-arm vibration syndrome; cases $11-15$ were evaluated as not due to an occupational disease. There were more pronounced abnormalities in the form of subjective symptoms and physical findings in cases $1-10$ than in cases $11-15$.

Before a person can be recognized as suffering from the hand-arm vibration syndrome the following criteria (issued by the Ministry of Labour in 1977) must 
Table 1. Diagnosis of suspected hand-arm vibration syndrome. ${ }^{a}$

\begin{tabular}{|c|c|c|c|c|c|c|c|c|c|c|c|c|c|c|c|}
\hline & \multicolumn{15}{|c|}{ Case number ${ }^{\mathrm{b}}$} \\
\hline & 1 & 2 & 3 & 4 & 5 & 6 & 7 & 8 & 9 & 10 & 11 & 12 & 13 & 14 & 15 \\
\hline \multicolumn{16}{|l|}{ Subjective symptoms } \\
\hline Coldness & + & + & + & + & + & ++ & + & + & . & + & + & + & + & + & \\
\hline Raynaud's phenomenon & ++ & . & . & + & . & ++ & ++ & + & + & ++ & + & + & + & + & + \\
\hline Numbness & + & + & + & + & + & + & + & + & + & + & $\cdot$ & + & + & . & + \\
\hline Pain & + & + & + & + & + & + & + & . & . & + & + & + & + & . & . \\
\hline Elbow joints & & & & & & & & & & & & & & & \\
\hline $\begin{array}{l}\text { Pain } \\
\text { Tests }\end{array}$ & ++ & + & . & + & + & . & + & + & + & + & . & + & + & . & \\
\hline Circulation & ++ & ++ & ++ & ++ & ++ & + & ++ & ++ & ++ & ++ & + & . & . & . & \\
\hline Nerve function & ++ & + & ++ & ++ & ++ & + & ++ & + & ++ & + & ; & + & + & + & $\because-$ \\
\hline Musculoskeletal & ++ & + & ++ & ++ & + & + & ++ & + & $+t$ & $+t$ & + & + & + & + & \\
\hline Radiographic & ++ & + & · & ++ & + & + & + & + & + & + & . & + & . & . & . \\
\hline \multicolumn{16}{|l|}{ Physical examinations } \\
\hline Cold hand & . & . & . & + & . & + & + & . & + & + & . & + & - & $\cdot$ & \\
\hline Hypoesthesia & + & + & + & + & + & . & + & + & + & + & + & + & . & + & \\
\hline Muscle tenderness & . & + & . & + & . & . & . & + & + & . & . & . & + & . & \\
\hline $\begin{array}{l}\text { Muscle atrophy } \\
\text { Disturbed movements }\end{array}$ & . & . & . & + & . & . & . & . & . & . & $\cdot$ & . & . & $\cdot$ & \\
\hline of elbow joints & ++ & . & + & $+t$ & . & + & . & + & . & . & . & + & + & . & . \\
\hline
\end{tabular}

a $+=$ light degree of disturbance, $++=$ marked disturbance.

- Cases 1-10 were diagnosed and recognized as hand-arm vibration syndrome.

be met: (i) the disease must be caused by the habitual use of vibratory tools for one year or more and (ii) the disease must include either pain or cold or stiffness, etc, that occurs intermittently or continuously in the fingers or arms. All of the following items, or one of them to a marked degree, are included: (i) peripheral circulatory disturbances in the fingers and arms, (ii) peripheral nervous disturbances in the fingers and arms, (iii) motor function disturbances due to abnormalities in bones, joints, muscles, tendons, etc, in the fingers and arms, and (iv) Raynaud's phenomenon. It is not necessary to demonstrate Raynaud's phenomenon in the fingers objectively. Hearing loss, lumbago, neck-shoulder-arm syndrome, and other conditions are recognized in other regulations. Although cases 2, 3, and 5 did not show Raynaud's phenomenon in the fingers, they were recognized as hand-arm vibration syndrome.

Thus, a health control of workers using vibratory tools is performed twice a year. The diagnosis of the disease is evaluated from the history of symptoms, physical examinations, and laboratory tests. Recording the history requires a great deal of skill, knowledge, and experience on the part of the physician. Above all, the patient-physician relationship is essential. On the basis of the annual examination the workers are divided into the following three categories: a healthy group, a group with suspected vibration syndrome or illness without therapy, and a group recognized as having the vibration syndrome with therapy.

\section{References}

1. Chang C. Cold water immersion test in patients with vibration disease. Jpn J Ind Health 18 (1976) 453-463.

2. Matoba T. Treatments of vibration disease and its longterm follow-up study. Jpn J Traumatol Occup Med 25 (1977) $447-453$.

3. Matoba T, Chiba M, Toshima H. Cardiovascular features of the vibration syndrome: An adaptive response. In: Brammer AJ, Taylor W, ed. Vibration effects on the hand and arm in industry. John Wiley \& Sons, New York, NY 1982, pp 25-30.

4. Matoba T, Itaya M, Toshima $\mathbf{H}$. Clinical pictures of cases with protracted course in vibration disease. $\mathrm{J} J$ pn Soc Intern Med 70 (1981) 546-552.

5. Matoba $T$, Kusumoto $H$, Mizuki $Y$, Kuwahara $H$, Inanaga $\mathrm{K}$, Takamatsu $\mathrm{M}$. Clinical features and laboratory findings of vibration disease: A review of 300 cases. Tohoku J Exp Med 123 (1975) 57-65.

6. Saito K. Diagnostic items. In: Saito K, ed. Vibration hazards as an occupational disease. Nankodo, Tokyo 1980, pp 33-44.

7. Saito K, Niioka M, Fujimoto S, Sibano N. Comparison of the cold water immersion tests at $5^{\circ} \mathrm{C}$ and $10^{\circ} \mathrm{C}$ for diagnosis of the vibration disease. Jpn J Ind Health 23 (1981) 33-41.

8. Sakakibara H, Miyao K, Kaneda S, Kobayashi A, Nakagoma T, Yamada S. Cold water immersion test for diagnosis of vibration diseases. Jpn J Ind Health 24 (1982) 672-686.

9. Tominaga Y. Physiological functions in workers with vibratory tools. In: Miura T, ed. Vibratory tools and prevention for vibration disease. Institute for Labour Science, Tokyo 1982, pp 201-222.

10. Yamada S. Primary factors for the occurrence of white waxy changes of the finger in vibration hazards with presentation of the nail press test. Jpn J Ind Health 14 (1972) 529-541. 